\title{
The effect of Fault Ride-Through requirements on voltage dips and post-fault voltage recovery in a Dutch Distribution Network
}

\author{
P. Karaliolios ${ }^{1}$, E.J. Coster ${ }^{1,2}$, J.G. Slootweg ${ }^{1,3}$, W.L. Kling ${ }^{1}$ \\ ${ }^{1}$ Department of Electrical Engineering, Eindhoven University of Technology \\ PO Box 513, CR. 2.04, 5600, MB Eindhoven, the Netherlands \\ Phone: +0031402473707, Fax: +0031402450735, e-mail: p.karaliolios@tue.nl, W.L.Kling@tue.nl \\ ${ }^{2}$ Stedin NetBeheer \\ Rochussenstraat 200, Postbus 1598, 3000BN Rottererdam \\ Phone: +31 10 4575167, Fax: +31 10457 7298, e-mail:e.j.coster@ stedin.nl \\ ${ }^{3}$ Enexis B.V. \\ P.O. Box 856, $5201 \mathrm{AW}$,'s-Hertogenbosch \\ Phone: +31 6 52376925, e-mail: han.slootweg@enexis.nl
}

\begin{abstract}
In this paper the possibility to use Decentralized Generation (DG) units for voltage support in Distribution Networks during and after a Short Circuit (S/C) event is discussed. Two types of DG units will be examined, Combined Heat-Power (CHP) plants and Doubly-Fed Induction Generators (DFIG). Earlier approaches would oblige the disconnection of these units during grid disturbances, in order to avoid unwanted conditions such as interference with the protection system and islanding [1]. Newer grid codes for Transmission Networks like [2], taking into consideration the increased share of these units in energy production have set specific Fault Ride-Through (FRT) criteria which oblige them to stay connected during SC events when they are combined to large plants directly connected to the transmission grid, such as (off shore) wind farms.. If ever more DG is connected directly to distribution grids, the same reasoning leading to applying rault ride through criteria to DG connected in large groups to transmission grids, may be applied to DG connected to distribution grids, as a loss of a a large amount of DG connected to distribution grids has the same adverse effect as using DG connected directly to the transmission grid.
\end{abstract}

In order to examine the effects of applying FRT criteria to DG connected to the distribution grid, simulations with a detailed modeled network for different types of outages were carried out. In the simulations, the application of FRT criteria currently only used for DG connected to the transmission grid is discussed. From the specific test case, which corresponds to a strong network with extended cable connections and locally high penetration level of DG in distribution system it was shown that application of strict fault ride-through criteria combined with active voltage support is not necessary in case of DG connected to distribution networks.

\section{Key words}

Fault Ride-Through behavior, CHP, DFIG, Distribution Network, voltage support

\section{Introduction}

The need of reducing $\mathrm{CO}_{2}$ emissions, to which many countries are forced by international agreements, such as the Kyoto protocol, has led to the introduction of alternative energy sources in electricity production. Due to the relatively low energy density of natural resources and the goal to use the heat released by electricity production useful, these sources are often of a far smaller scale than conventional power plants and hence form distributed generation. Early approaches would require that DG would disconnect during system voltage drops [4]. However the increasing penetration level of DGs, which now, in many countries contribute significantly, has led to a change of policy from system operators. Several grid codes require from distributed generators connected in large groups to a transmission network (such as wind farms) to stay connected and participate actively in voltage control during normal and emergency situations, by demanding the DG to conform to specific criteria, known as FRT requirements.

Examples of such requirements can be found in [2] for Germany and to a lesser extent also in [3] for the Netherlands. They prescribe that DG units should remain connected to the network for a specific time which depends on the depth of the voltage dip in the point of connection. During the disturbance they are obliged to support the network with a specific amount of reactive power which can reach up to 1.1 p.u. Both of these grid codes do not take into consideration small DG units connected in the distribution level. In [2] strict FRT requirements are formulated, which however only apply to large groups of DG connected to the transmission grid; in [3], all units above $5 \mathrm{MW}$ are addressed, with small differences depending on the voltage level to which the DG is connected and these FRT criteria are less strict. 


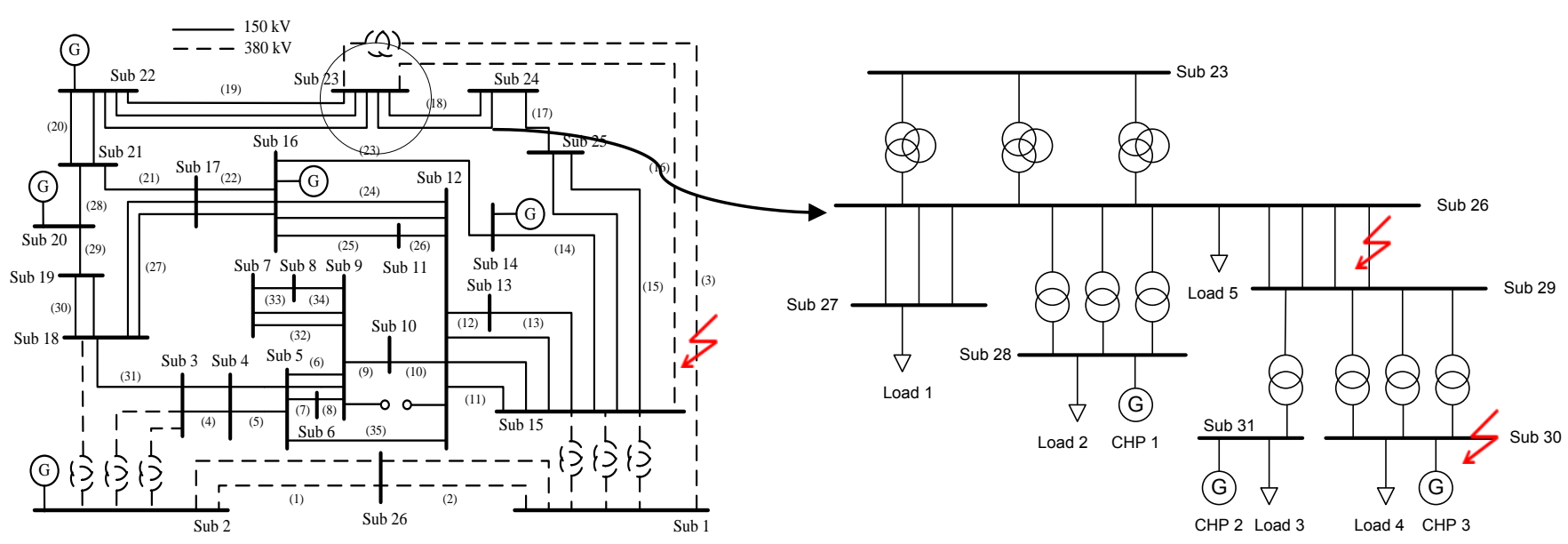

Figure 1: Network Schematic

In the Netherlands, no criteria are imposed on DG below a rating of $5 \mathrm{MW}$, In case of $\mathrm{CHP}$, manufacturers and operators chose for a pick up voltage 0.8 p.u. with a delay of $100 \mathrm{~ms}$ themselves. In [5] it has been shown that a time setting of the undervoltage protection up to $200 \mathrm{~ms}$ is not endangering the stability of the generators. With this time setting DG can survive all the S/C occurring in the high voltage grid, providing them the potential to be able to participate actively in the voltage support during and after the $\mathrm{S} / \mathrm{C}$. In case of the DFIG, quick disconnection after detection of a voltage drop by the controllers of the power electronic converter, tends to be used to protect the installation.

In this paper, the application of strict FRT criteria to DG connected to distribution grids is investigated. This may be important in the future, if ever more DG is connected to distribution grids. In the first part of the paper the network that is used as a case study is presented, together with the models of the DGs used for the simulation. Then, the proposed FRT settings for the DFIGs and their implementation are discussed. Finally the impact of these settings on voltage recovery is discussed by analyzing different types of $\mathrm{S} / \mathrm{C}$ which result in different voltage dips.

\section{Models}

\section{Network Model}

In order to investigate the behavior of different types of DG during various voltage dips, an existing grid that is currently operated in Netherlands is used as a study case. In this model a large area is covered, which, as it can be seen in Fig. 1, consists of a national transmission grid operating at $380 \mathrm{kV}$, with connections to the local transmission grid at 3 points (substations 1, 2 and 23 respectively).

The local transmission grid operates at $150 \mathrm{kV}$. On this level, several heavy industries like refineries, chemical plants etc are connected. In most of them large CHP plants rated up to $60 \mathrm{MVA}$ are installed.
The distribution grid connected to the substation 23 is located in a greenhouse area and contains a large penetration of CHP-plants. The substation 23 is connected to the transmission grid via $150 / 25 \mathrm{kV}$ transformers. The $25 \mathrm{kV}$ side of the transformers is grounded through a $10 \Omega$ resistor.

The local distribution network, which is of radial structure, is operating at $10 \mathrm{kV}$, with the neutral point of the transformers ungrounded.

\section{CHP-Plant Model}

A CHP-plant is a gas engine which drives a synchronous generator. Manufacturers of the installed CHPs provide data for the proper modeling of the generator, which are used as parameters in the synchronous machine model available in DIgSILENT Powerfactory. A $5^{\text {th }}$ order model is used to represent the synchronous generator. It has to be mentioned that the dynamics of the gas engine are neglected and its inertia is incorporated in the inertia of the synchronous machine.

All CHP-plants are equipped with an Automatic Voltage Regulator (AVR), which is also modeled. Currently, CHP-plants do not contribute actively to the voltage regulation and the AVR is used as a power factor controller. Further, voltage control by synchronous generators is characterized by relatively long time constants due to the large reactances of rotor and stator.

\section{DFIG Model}

For the simulations with the DFIG wind turbines, the generic model provided by DIgSILENT is used. In this model both mechanical and electrical parts are considered. The wind turbine is modeled with a two-mass shaft system, which is proved to be adequate for transient calculations [6].

Grid and rotor-side converters are represented as fundamental frequency voltage sources in the neglecting semiconductor switching phenomena in the six-transistor 


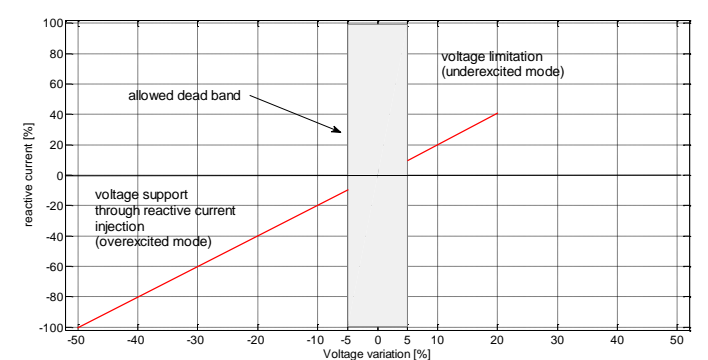

Figure 2 German voltage support curve [2]

bridge. All the internal controls are modeled in detail. The grid-side converter also incorporates routines to contribute to voltage support as proposed in [7]. Wind turbines have various protection systems, in order to ensure their proper operation during fault conditions such as over-speed, over-voltage and under-voltage. Apart from the basic protection routines, which are incorporated in the model, the DFIG uses also a crowbar in order to protect the converter from excessive currents which occur during severe transients, such as voltage dips and S/C clearances. The effect of crowbar protection in the enhancement of the stability as well as the fault ride-through capability of the generator has been discussed extensively in [7]. In [8] it is also shown that it affects the S/C contribution of the generator; therefore, it is also incorporated in the model used for the simulations presented in this paper.

\section{DG responses to voltage drop}

As it is mentioned in the introduction, undervoltage protection settings for small CHP units in the Netherlands would oblige disconnection for a sustained voltage dip of 0.8 p.u. lasting more than $100 \mathrm{~ms}$. As it has been shown in $[5 ; 9]$ this could result in the disconnection of a big amount of DG. An adaptation to longer time settings prevents this phenomenon and gives the opportunity to the DG to participate in active voltage support.

In the DFIG, the existence of power electronic converter gives extra possibilities for the control of the active and reactive power with a speed which makes it applicable to be used for voltage support during and after voltage drops. As it is mentioned before, from wind turbines connected to the transmission system, active voltage support during and after $\mathrm{S} / \mathrm{C}$ it is required already in some countries. This requirement is fulfilled by adequately controlling the reactive power of the generator according. In the simulated case, the wind turbines were assumed to be responding according to Fig. 2.

As can be concluded from the figure, the generator should allow a dead band of $\pm 5 \%$ and respond within 20 $\mathrm{ms}$ of the disturbance with a gain for the converter of at least 2 . Further, the generator should be able to provide the nominal current for a $\mathrm{S} / \mathrm{C}$ resulting in voltage dip of $50 \%$ in the low voltage side of the generator(Fig. 2.).
Additional control routines in the grid side converter, which is also responsible in normal operating conditions to keep the correct power factor, are needed to make a DFIG comply with these requirements. The power stored in the DC link can be used for the voltage support scheme during the and after the voltage drop, by changing the reactive current reference signals. It has to be mentioned that even when the crowbar is connected, which results in loss of control of the generator and blocking of the rotor side converter, the grid side converter can still provide reactive power if the DC link stays stable. In [10] it is proposed to add a chopper in the DC link to enhance its stability, but in this paper it is not considered.

Synchronous generators provide possibilities to control voltage by adjusting the excitation current through the AVR. Simulations have shown that the use or not of the AVR does not affect the voltage support during S/C period and has a small impact during the post fault voltage recovery. This is due to the large reactance of the armature which results in time constants bigger than the examined events, therefore the option to use CHPs for active voltage support is not considered here.

\section{Results}

For the evaluation of the effect of FRT strategies in the voltage recovery 3 different $\mathrm{S} / \mathrm{C}$ events were simulated, namely in:

- $\quad$ EHV OHL \#3

- a $25 \mathrm{kV}$ cable

- a cable close to the $10 \mathrm{kV}$ substation as depicted in Fig. 1.

Due to the fact that 3-ph $\mathrm{S} / \mathrm{C}$ cause the biggest disturbance, only these are presented.

The first S/C event occurs in the transmission system, in the $380 \mathrm{kV}$ line 3 . The characteristic of these types of S/C in contrast with the other two is that they affect a very large area, as it can be clearly observed in Fig.3. Currently most of the HV network in the Netherlands is Over-Head Lines (OHL) and for the protection scheme reclosers that are able to clear the $\mathrm{S} / \mathrm{C}$ in a period of 100 $\mathrm{ms}$ are used. With current protection settings for DG

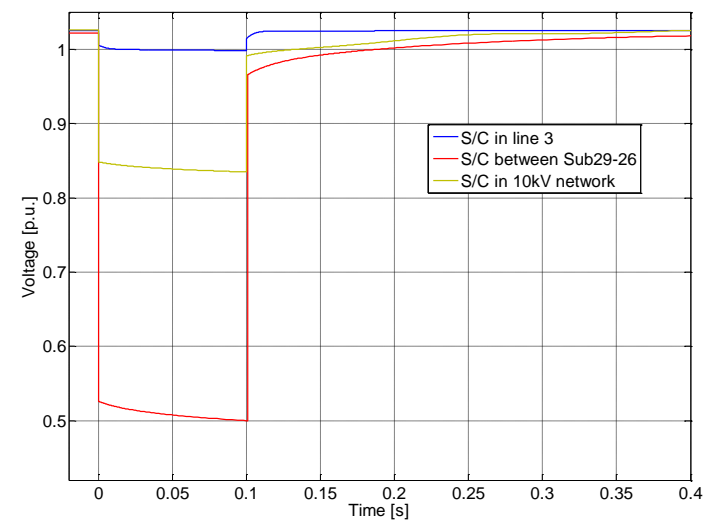

Figure 3 Voltage in Sub23 


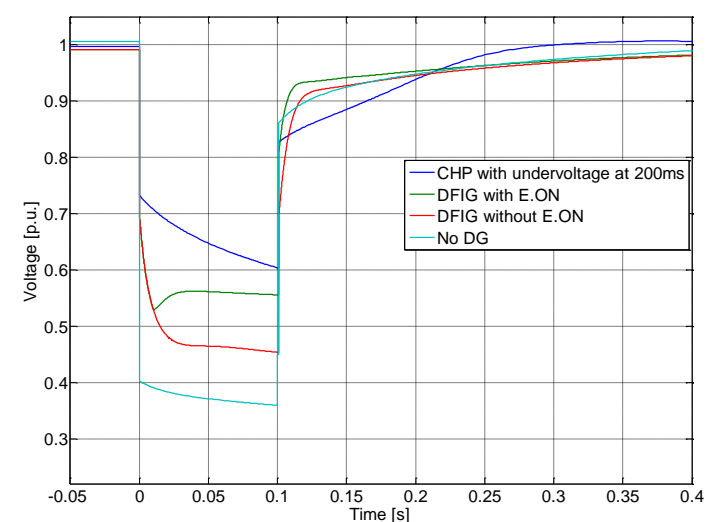

Figure 4 Voltage in $10 \mathrm{kV}$ Substation during $\mathrm{S} / \mathrm{C}$ in line 3

units, a large amount of DG is disconnected, but with time settings of $200 \mathrm{~ms}$ DG can still stay connected and therefore participate in the voltage support [5;9]

The other two S/C occur in the cable network, in different voltage levels and at various distances from the DG units. The current protection scheme in the cable network uses overcurrent protection which has a response time of around $300 \mathrm{~ms}$. In this case the faulty feeder is disconnected from the system. With this time response, the stability of the DG is endangered, particularly for those near the event. In [11] a new protection strategy is proposed which can ensure much faster response times. In order to be able to make a direct comparison between the selected cases, the duration of the $\mathrm{S} / \mathrm{C}$ in the $25 \mathrm{kV}$ cable was also set at $100 \mathrm{~ms}$.

\section{Discussion}

By comparing the curves in Fig. 3 and 4 the MV voltage level in the distribution network remains much higher than if the DG would be obliged to disconnect immediately, although the $\mathrm{S} / \mathrm{C}$ in overhead line \#3 causes a voltage dip in an extended area and big voltage drop in substation \#23.

In the case of the CHP (blue line) due to the high $\mathrm{S} / \mathrm{C}$ contribution of the synchronous generator the voltage is kept at much higher levels than in case of the DFIG. The application of extended time tripping ensures that units

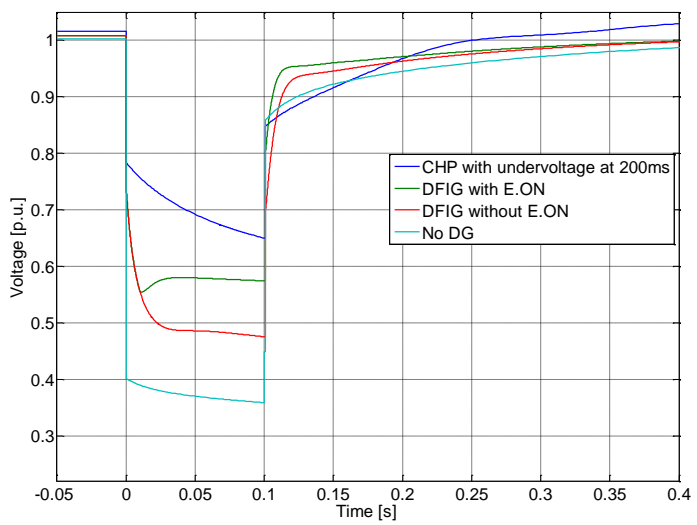

Figure 5 Generator terminal voltage during $\mathrm{S} / \mathrm{C}$ in line 3

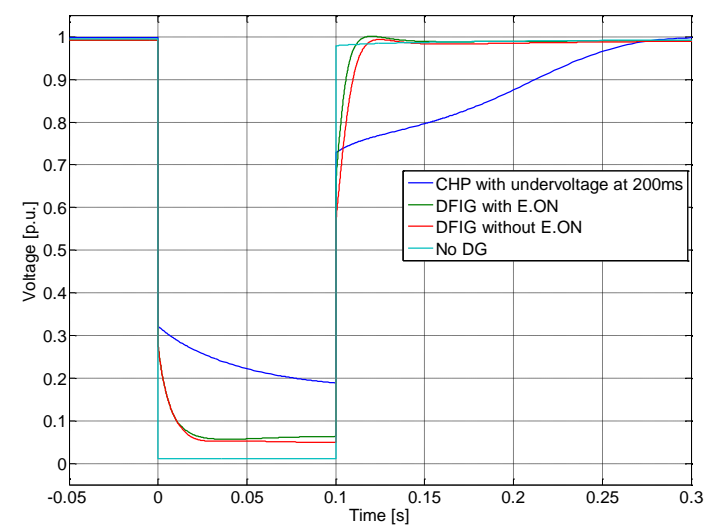

Figure 6 Voltage in $10 \mathrm{kV}$ Substation during S/C in a $25 \mathrm{kV}$ line

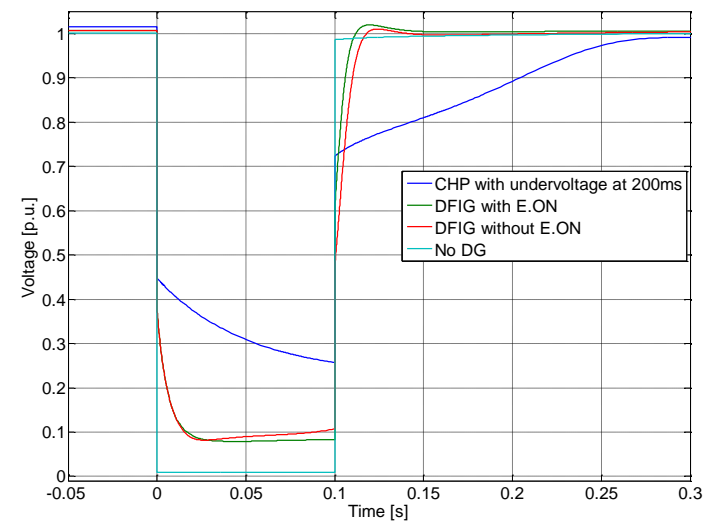

Figure 7 Generator terminal voltage during $\mathrm{S} / \mathrm{C}$ in $25 \mathrm{kV}$ line

will stay connected after the clearance where due to the reactive power absorption [5], however, the CHPs delay the voltage recovery.

In the case of the DFIG, as the voltage dip across the terminals of the generator is slightly deeper due to their lower fault contribution, but still (Fig. 5) the units are able to supply reactive power when controlled accordingly (green line). In this case an improvement of the voltage level by $10 \%$ is achieved in comparison to DFIGs which do not supply reactive power (red line).

The case of the $\mathrm{S} / \mathrm{C}$ in the $25 \mathrm{kV}$ cable is different from the previous one in terms of the area affected and the disturbance caused in the distribution grid (Fig. 6). Due to the very low voltage in the terminals of the generators (Fig.7) the DFIGs fail to contribute significantly to voltage support no matter what FRT behavior is chosen to follow (red and green line on Fig. 6;7).

The CHP still manages to support the voltage during the $\mathrm{S} / \mathrm{C}$ due to its high $\mathrm{S} / \mathrm{C}$ current, but after the clearance of the $\mathrm{S} / \mathrm{C}$ it postpones significantly the restoration of the voltage levels due to its reactive power consumption. With time settings for the undervoltage protection at 200 ms and pick up voltage at 0.8 p.u. it can be seen that the triggering of the protection after the clearance of the S/C is still avoided. 


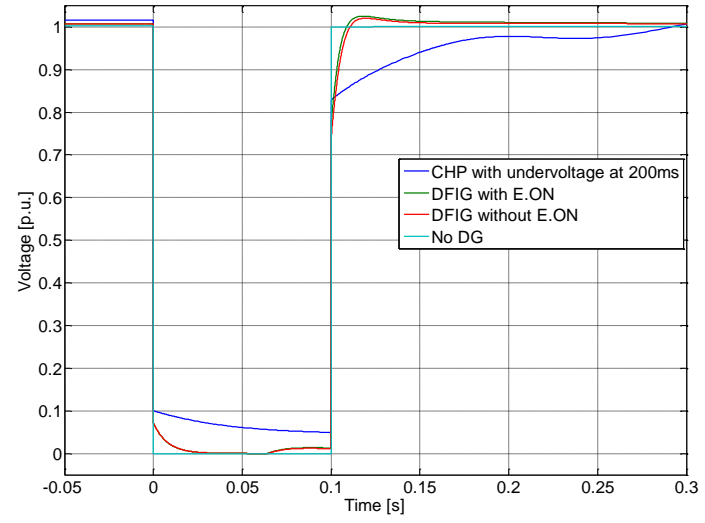

Figure 8 Generator terminal voltage during $\mathrm{S} / \mathrm{C}$ in $10 \mathrm{kV}$ cable

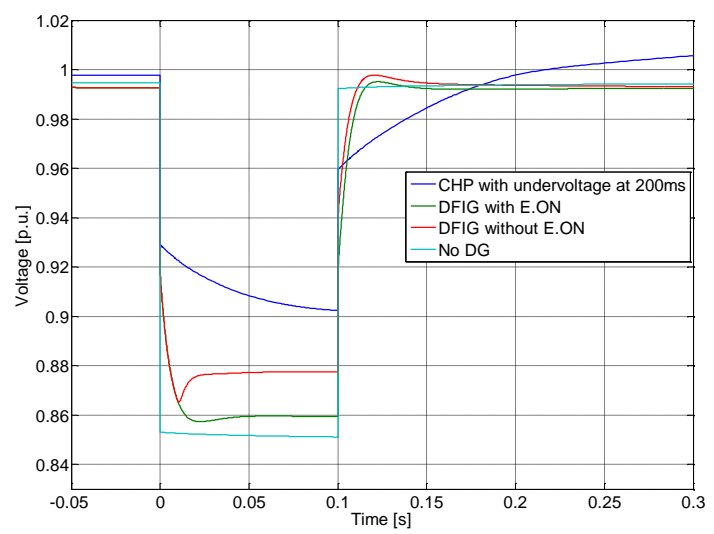

Figure 9 Voltage in $10 \mathrm{kV}$ Substation during S/C in $10 \mathrm{kV}$ cable

Finally a S/C that occurs close to the generator terminals is examined.. Due to the very low voltage across the generator terminals (Fig. 8), again the application of active voltage support to DFIGs fails to offer any significant results. Furthermore this type of S/C causes big transients in the DC link of the DFIG which further limits the possibilities to provide the requested reactive power according to Fig.2.

Due the different deeper voltage drop cause by the $\mathrm{S} / \mathrm{C}$ at the $25 \mathrm{kV}$ level, in comparison with the $\mathrm{S} / \mathrm{C}$ at the $10 \mathrm{kV}$ level, the behavior of the system under the CHP scenario after the S/C clearance is different. It can be observed that the delay of the voltage recovery in the S/C of the 25 $\mathrm{kV}$ line is longer. The deeper voltage drop increases the reactive power consumption of the $\mathrm{CHP}$ after the clearance of the S/C and postpones the settling of the voltage to its previous levels (Fig. 6;9).

In general, for the DFIG there is a significant difference in the time it takes till the voltage recovers above the 0.8 p.u. compared to the CHPs as it is depicted in Fig. 7and 8 with red and blue line respectively. This is primarily caused by the fact that in case of a DFIG, the generator is not drawing reactive power from the grid because it is partially decoupled by the converter connected to the rotor. However, it makes no significant difference whether FRT requirements are used or not. The application of FRT requirements slightly accelerates voltage restoration slightly reduces the overshoot of the voltage during the restoration (Fig 6,9), since the operation point of the converters is moved to the first quadrant by starting to consume reactive power while generating active power (Fig. 2).

It has once more to be mentioned that if a pick-up time of $100 \mathrm{~ms}$ was applied, as is currently normally the case, a large number of DGs would have disconnected.

\section{Conclusions}

In this paper an investigation of how FRT criteria affect voltages in distribution system during and after disturbances is made. Two different types of DG are connected to a practical network and then compared using simulations.

In general, for large system disturbances, which are not close to the generators, and generator terminal voltage remains high enough to be able to support the network through reactive power injection, the implication of FRT has positive effects. For S/Cs that occur close to the generator terminals and cause locally a big voltage dip, the application of the FRT does not bring significant improvement, since voltage support through reactive power is not possible.

During the post-fault period, the partial decoupling from the grid of the DFIG by the rotor converter has a positive effect on the voltage recovery, in contrast with the CHPs, where remagnetizaton can cause a strong delay in the voltage restoration. The application of active voltage support does not show significant improvement, either in the case of CHPs or of DFIGs.

Concluding, it can be stated that for cable networks with short distances and high S/C capacity, the introduction of strict FRT requirements does not give significant improvement in the voltage support and recovery of the distribution network.

\section{Acknowledgements}

This research has been performed within the framework of the IOP-EMVT research program 'Intelligent Power Systems' that is supported financially by SenterNovem. SenterNovem is an agency of the Dutch Ministry of Economic Affairs.

\section{References}

[1] P. P. Barker and R. W. De Mello, "Determining the Impact of Distributed Generation on Power Systems: Part 1 - Radial Distribution Systems," 3 , 1645-1656. 2000. Piscataway, NJ, USA, IEEE.

[2] " German Grid Code: Transmission Code 2007 Network and System Rules of the German Transmission System", August 2007. 
[3] NMa Energiekamer, "Systeemcode," http://energiekamer.nl/images/Systeemcode_28_fe bruari_2009_tcm7-127999.pdf, Febr. 2009.

[4] "IEEE Standard for Interconnecting Distributed Resources with Electric Power Systems," IEEE Std 1547-2003, pp. 0-16, 2003.

[5] E. J. Coster, J. M. A. Myrzik, W. L. Kling, "Effect of Grid Disturbances on Fault-Ride-Through Behaviour of MV-connected DG-units, in especially CHP-plants," Integration of Wide-Scale Renewable Resources Into the Power Delivery System, 2009 CIGRE/IEEE PES Joint Symposium, 2009.

[6] J. H. Slootweg, "Wind Power: Modeling and impact on power system dynamics," PhD Thesis Technical University of Delft, 2003.

[7] I. Erlich and F. Shewarega, "Modeling of Wind Turbines Equipped with Doubly-Fed Induction Machines for Power System Stability Studies, "Power Systems Conference and Exposition, 2006.PSCE '06, pp. 978-985, 2006.
[8] P. Karaliolios, A. Ishchenko, E. Coster, J. M. A. Myrzik, and W. L. Kling, "Overview of shortcircuit contribution of various Distributed Generators on the distribution network," 43rd International Universities Power Engineering Conference, UPEC 2008, pp. 1-6, 2008.

[9] P. Karaliolios, E. Coster, W. L. Kling, and J. M. A. Myrzik, "Fault Ride-through Behavior of MVconnected Wind Turbines and CHP-plants during Transmission Grid Disturbances," UPEC 2009, 2009.

[10] I. Erlich, J. Kretschmann, S. Mueller-Engelhardt, F. Koch and J. Fortmann, "Modeling of wind turbines based on doubly-fed induction generators for power system stability studies," 1-8. 2008.

[11] E. J. Coster, J. M. A. Myrzik, and W. L. Kling, "Transient stability of DG in MV-ring networks," IEEE T0026D conference Chicago, 2008. 